Est Ag 52 (2017) 9-23

\title{
Semblanza de Senén Vidal García
}

(10/XI/1941, San Pedro de Trones, León 11/IV/2016, Salamanca)

MARCIANO VIDAL GARCÍA

Escribo esta semblanza de mi hermano Senén como expresión del cariño de toda la familia -hermanos y sobrinos- hacia él. Como fácilmente comprenderá el lector, no están aquí expresados todos los datos objetivos ni mucho menos todos nuestros sentimientos. Confío haber recogido los más sobresalientes y los más significativos de los que componen el archivo de nuestra memoria familiar sobre Senén.

Me resulta difícil ver a Senén en situación estática. Prefiero contemplarlo en movimiento, en interacción. De ahí que trate de expresar su semblanza situándolo en sucesivos contextos o encuadres. Su semblanza nace, pues, del diálogo entre el fondo y la figura. Diez expresiones pueden dar título a las diez imágenes que integran esta breve semblanza de Senén Vidal García (1941-2016): pueblo, familia, hogar sacerdotal, cultura, cátedra, libro, parroquia, hondón, misterio, resurrección.

\section{Un PUEBLo -SAN PEDRo de Trones (León)- COMO REFERENTE CONTINUO}

Senén nació el 10 de noviembre de 1941. No resaltaré las implicaciones de la cronología, marcada por una situación todavía post-bélica en la que la precariedad económica y la carencia de libertades cívicas no impedía la alegría del vivir y el afán por la superación. Senén, como tantos otros niños y muchachos españoles de su momento histórico, fue troquelado en los valores de la austeridad, de la solidaridad, del trabajo, del amor a la familia, de la fidelidad a la palabra dada, de la religiosidad connaturalmente asumida. El esfuerzo personal se situó dentro de esos parámetros axiológicos, los cuales no mermaron sino que potenciaron la valía de lo conseguido mediante el trabajo propio. 
Me detengo más en la influencia de la geografía. Senén tuvo siempre como referente de su vida el pueblo en que nació: San Pedro de Trones, situado en el extremo suroccidental de la provincia de León (España), dentro de la diócesis de Astorga. Con testimonio documental del s. XIII en el Tumbo viejo del monasterio de San Pedro de Montes, conservado en el archivo catedralicio de Astorga, el poblado de San Pedro el Otro (de donde, probablemente, derivó al de Trones) existía ya en la alta Edad Media. Por datos arqueológicos conocidos por los vecinos del pueblo -enterramientos romanos y un ara de altar romano- se puede retrotraer la existencia de un asentamiento humano a la época romana, como lugar de vigilancia de la explotación aurífera de las Médulas que se halla a la vista mirando, hacia el norte, a la otra vertiente del río Cabrera.

Cuando Senén nació, el pueblo vivía de la explotación de la pizarra, una roca especial compuesta de láminas que sirvieron en otro tiempo para la escritura y que son utilizadas hoy para cubiertas de tejados o para pavimentación de edificios. Siendo España el primer país en producción y en exportación de pizarra, la zona en que está situado el pueblo de San Pedro de Trones es uno de los enclaves más importantes de esa explotación.

Recostado en la falda norte de la montaña, San Pedro de Trones goza de una vista espléndida en un amplio radio de visibilidad, exceptuado el sur. A Senén le gustaba el pueblo en que nació. En la iglesia parroquial -en la vieja y en la hermosamente renovada- expresó y maduró su fe. En la escuela del pueblo se inició en el saber. Al pueblo retornaba siempre que podía.

Como normal contrapartida, puedo afirmar que la gente del pueblo le quería mucho. Senén era de fácil y llano trato. Siempre alegre y en actitud positiva. Siendo tan inteligente y teniendo tantos conocimientos, no dejó nunca de ser del pueblo y de pertenecer al pueblo. Sirvan como expresión de lo dicho dos detalles.

Cuando no existía piscina en el pueblo, los chicos y las chicas -y también los mayores- si querían remojarse en verano tenían que bajar a uno de los dos ríos que, después de haber recorrido el uno La Cabrera y el otro El Bierzo, se dan el abrazo a la salida del leonés pueblo de Puente de Domingo Flórez o del gallego pueblo de Quereño. Pues, bien, en muchos días de las vacaciones veraniegas, Senén conducía a un buen grupo de chicos a bañarse en uno de los dos ríos, generalmente en el río Sil frente a la estación de tren de Quereño. Y no solo los conducía, sino que también les enseñaba a nadar. Son muchos del pueblo -ahora personas mayores- que de- 
claran haber aprendido a nadar bajo la dirección -exigente, sí, pero siempre afable- de Senén.

El segundo detalle tiene que ver también con la diversión. Pero, ahora, se trata de la diversión en el bar. Senén había aprendido a jugar bien a las cartas, sobre todo en el juego de la brisca y del tute. No jugaba tan bien como otro de sus hermanos, Arsenio, quien era tenido como el mejor jugador de cartas en una amplia zona de pueblos del contorno. Sin llegar a esa perfección, Senén era capaz de competir con los mejores jugadores del pueblo. Mediante esta actuación su cercanía con la gente era más patente y quedaba mejor asegurada.

La querencia entre el pueblo y Senén fue recíproca. Se puso en evidencia cuando, haciendo coincidir fechas, Senén y yo celebramos en el pueblo los cincuenta años de sacerdocio. No fue solo nuestra fiesta; fue una fiesta -religiosa y humana- de todo el pueblo. Con tal motivo, Senén recibió de manos del alcalde una placa de reconocimiento de los vecinos del pueblo.

El pueblo se volcó en acogida respetuosa y cariñosa cuando Senén, muerto en Salamanca el día 11 de abril de 2016, fue velado la tarde del día 12 y enterrado al día siguiente en el cementerio del pueblo. En la Eucaristía de corpore insepulto, concelebrada por un nutrido grupo de sacerdotes (de los pueblos vecinos, redentoristas, tres operarios y de la diócesis de Astorga, entre ellos el vicario general en representación del obispo), la gente del pueblo y de los pueblos de los alrededores expresaron su gran cariño a Senén y a su familia.

Sin tener un conocimiento muy preciso de ello, creo que Senén ayudó cuanto pudo a todos sus paisanos que acudieron a él con una solicitud. Se comprende que algunos padres que enviaban a sus hijos a estudiar a Salamanca pensaran en la posible ayuda del sacerdote del pueblo que residía en esa ciudad. Sin precisar detalles, sí era conocida la actitud y la práctica de caridad que tenía Senén frente a necesidades que podía solucionar según sus posibilidades.

\section{UNA FAMILIA AMPLIA: LUGAR DE ENTREGA Y DE ACOGIDA}

La relación con su pueblo la realizaba Senén desde su vinculación con la propia familia. Nació en una familia sencilla, compuesta por los padres, de los que disfrutó durante mucho tiempo, y por 10 hermanos contándose él entre ellos. 
Su padre, Faustino, fue profundamente religioso. Era también una persona instruida. Sin título oficial, hizo de maestro en el pueblo, enseñando a escribir y las cuatro reglas a bastantes paisanos. La madre, Margarita, fue una gran trabajadora; poseía notables habilidades naturales. Tan pronto cocinaba y lavaba como hacía ella misma unas alpargatas, teniendo como hilo fuerte el que le traían sus hijos de las bombas explotadas con motivo de las fiestas.

Senén fue especialmente querido por sus padres. Cuando profesó su hermana Sara (sor Delia), lo llevaron sus padres a Plasencia. La madre nos contaba, con orgullo, que todos se admiraban de la buena educación que tenía su niño Senén.

En los papeles personales de Senén se puede constatar la gran cercanía que tenía con su padre y, más aún, con su madre. Expresó su dolor por la muerte del padre a través de estos versos:

"Se me parte el corazón

por la carne más caliente.

Se me rompen las palabras,

como cacharros agrietados.

Aquí tenéis los restos.

¡El grito,

mi grito,

y el de todos vosotros,

lo contengo!"

(Salamanca, 25.2.1984)

Senén vino de Washington para acompañar a su madre en los últimos momentos. Él estaba convencido -nosotros, sus hermanos, también lo estábamos- de que su madre había esperado a morir para verlo a él.

En el orden de venida a este mundo, Senén era el antepenúltimo de los hermanos, el octavo de diez hermanos: dos mujeres y ocho varones. Las mujeres, Sara (entró en las Josefinas Trinitarias y en esa congregación vivió y murió) y Antonia, tenían una querencia especial hacia Senén. Antonia, como soltera que permaneció toda su vida en la casa paterna, era quien nos atendía a los que estábamos fuera. Por otra parte, Sara (sor Delia), al haber sido destinada a atender la ropería del Aspirantado de los Operarios diocesanos en Salamanca, coincidió allí durante algún tiempo con Senén. De las homilías más sentidas y profundas que le escuché a Senén, la más profunda en fe cristiana y la más sentida en afecto 
fraterno fue la que pronunció en el funeral de Sara de corpore insepulto en Madrid.

Senén también fue especialmente querido por sus hermanos varones (Gregorio, Rafael, Arsenio, Marciano, Gerardo, Laudelino, Cástor), por las cuñadas (Maximiliana, Benilde, María Consuelo, Teresa, Rosa) y por los sobrinos (y re-sobrinos). Sirvan de recordatorio estos detalles: algunos veranos disfrutados en las playas de Ortigueira y de Sanxenxo junto con hermanos y sobrinos; los encuentros con sobrinos, programados en Salamanca, con comida incluida; las celebraciones de toda la familia en el pueblo, en cuya preparación Senén era el estratega principal. Hay un sobrino que lleva el nombre de Pablo, porque nació en la época en que Senén estaba afanado en escribir su trabajo de tesis doctoral sobre la Resurrección en las cartas de san Pablo.

Senén vio morir a los padres, a sus dos hermanas y a un hermano (Gerardo), a dos cuñadas (Rosa y María Consuelo), y a un sobrino (Miguel Ángel). Su muerte, por muerte y por inesperada, causó un auténtico terremoto en la familia. Esta quiso tener sus restos en el cementerio del pueblo donde nació. Allí descansa Senén con el único título de Sacerdote operario diocesano y con la expresión de la esperanza en la Resurrección, sobre la que escribió su último libro, mediante la fórmula paulina: "El que resucitó a Cristo también dará vida a nuestros cuerpos mortales" (Rom, 8,11).

\section{Un HOgar SACERdotal: La Hermandad de SACERdotes Operarios}

Senén no se quedó en el pueblo ni realizó su proyecto personal como lo han hecho la mayor parte de sus hermanos varones. Ya hemos dicho que Sara se había ido con las Josefinas Trinitarias de Plasencia. Yo también me había ido con los Redentoristas. Él va ahora con los Sacerdotes Operarios de Salamanca.

Del pueblo procedía y al pueblo volvía con frecuencia un sacerdote nacido en el mismo pueblo: don Ceferino García Vidal, primo de nuestro padre. Terminó el servicio sacerdotal siendo deán de la catedral de Plasencia, responsable diocesano de catequesis y director de peregrinaciones. Dedicó sus últimos años (y sus recursos económicos) a edificar, en el lugar primitivo de una ermita del pueblo (posiblemente, del s. X), una preciosa iglesia neo-románica dedicada a la Virgen de la Estrella en un altozano desde donde se divisan otros doce pueblos pertenecientes a $\mathrm{La}$ Cabrera, a Valdeorras, y al Bierzo. 
Don Ceferino fue un suscitador de vocaciones sacerdotales (y religiosas) en San Pedro de Trones. Tres de sus sobrinos fueron ordenados sacerdotes en el mismo pueblo: el jesuita Dacio, el operario diocesano Primitivo, el sacerdote de Plasencia (y, después, obispo de Ávila y de Tenerife) Felipe. Otros dos sobrinos fueron sacerdotes claretianos: Domiciano y Federico. A los claretianos también perteneció Jesús Álvarez y, más tarde, Amador García. De los franciscanos había pasado a la diócesis de Astorga Isaac Núñez. Yo estaba con los redentoristas.

Senén fue del grupo de chicos que desde el pueblo dirigieron sus pasos hacia el Aspirantado "Maestro Ávila" (sobre un edificio del s. XVI, perteneciente, entonces, a los jesuitas) de los operarios diocesanos en Salamanca, donde ingresó el 4 de octubre de 1952. Hizo el año de probación en Tortosa desde el 31 de octubre de 1960 al 1 de noviembre de 1961, fecha esta última en que se incorporó a la Hermandad.

Muerto Primitivo Fernández, fue el único que permaneció como operario diocesano. A los de mi generación no descubro ningún secreto si recuerdo que los aspirantes a operarios diocesanos eran tenidos entonces -ojalá también lo sigan siendo ahora- como la crema de los seminaristas. Al pertenecer a un grupo religioso más humilde, yo siempre miré con cierta envidia el elevado status de mi hermano Senén.

No quiero entrar en la descripción de los estudios, tanto medios como filosóficos y teológicos, de Senén en Salamanca. Obtuvo la licenciatura en teología por la Universidad Pontificia de Salamanca en 1965 y fue ordenado sacerdote el 11 de julio de ese año en la ciudad del Tormes, quedando incardinado en la Hermandad.

Pero sí quiero hacer una pausa en el pueblo, en una larga tarde de aquellas que componían las vacaciones veraniegas, y hacer coincidir por arte de magia ese conjunto de personas cuyos nombres he escrito en un párrafo precedente. Pocos pueblos podrán presumir de aquello que se decía con cierta envidia y con una pizca de sorna: en este pueblo se podría crear una facultad de teología, al menos en cuanto a profesorado se refiere. Vedlo si no: había profesor de Dogmática (Domiciano Fernández), profesor de Historia de la Iglesia (Jesús Álvarez), profesor de Sagrada Escritura (Senén Vidal), profesor de Moral (Marciano Vidal), profesor de Sociología (Felipe Fernández), profesor de Psicología (Primitivo Fernández), etc. Sirva esta boutade para recordar el ambiente eclesial del pueblo en el que creció la vocación sacerdotal de Senén. 


\section{LA CULTURA: COMO ÁMBITO DE DISFRUTE Y DE TRABAJO}

El ámbito continuo de Senén fue la cultura, en el amplio sentido de este término. Además, me refiero tanto a la cultura civil como a la cultura eclesiástica. Dios le dotó con notables aptitudes para ello. Y él puso de su parte el esfuerzo y el empeño.

Senén heredó el buen oído musical de nuestro padre. Cuidó la música. En reuniones familiares -las de fin de año eran las más sonadas- animaba el ambiente con su amplio repertorio de canciones.

Sin descuidar las ciencias, las letras fueron su atracción. Le gustaba la literatura. Entre los poetas españoles modernos, tenía predilección especial por Antonio Machado. En su época del Aspirantado (bachillerato o estudios medios) hubo allí un interés especial por el cultivo de la literatura. No en vano por aquellos años se fraguó una generación de poetas en el mundo eclesiástico en torno a figuras vinculadas, de un modo u otro, con la Hermandad de Operarios Diocesanos (colegio español de Roma).

En el Aspirantado nació la revista Ajedrez, de orientación preferentemente literaria. Senén colaboró en ella. Creo que llegó a dirigirla, al menos en algunos de sus números. Uno de los dibujantes de la revista fue su hermano Cástor.

La cultura civil, en sus variadas vertientes (música, literatura), fue el telón de fondo del quehacer y de los afanes de Senén; también constituyó el ámbito al que retornaba para satisfacer necesidades estéticas: escuchar música, leer poesía (en general, literatura). Pero, fue la cultura religiosa la que ocupó la mayor parte de su vida. Según he anotado, hizo los cursos de filosofía y de teología en la Universidad Pontificia de Salamanca. Tuvo que sobresalir entre sus compañeros, ya que -según me ha confesado el sacerdote operario don Luis Rubio, biblista reconocido- él mismo indicó a los superiores de la Hermandad la conveniencia de que Senén fuera encaminado hacia la especialización en los estudios bíblicos.

La indicación fue atendida positivamente. Senén, en posesión del título de licenciatura en teología, fue destinado a Roma (Pontificio Colegio Español de San José) a fin de cursar (1965-1968) en el Pontificio Instituto Bíblico la licenciatura en Estudios Bíblicos, título que obtuvo en 1968. Coincidimos algún tiempo los dos en Roma, él especializándose en Biblia y yo en Teología Moral. Recuerdo que él me acompañó en la defensa de la tesis doctoral en la Academia Alfonsiana y en la posterior frugal celebración en un bar de la via Merulana. 
Me alegré poder devolverle la visita cuando, junto con otros hermanos y amigos, le acompañé en su defensa de tesis doctoral en Teología Bíblica sostenida en la facultad de teología de la Universidad Pontificia de Salamanca (1979). Fue aquella una celebración académica, sí, pero también una fiesta familiar. La familia se sintió orgullosa de Senén y estoy seguro de que él también se sintió contento de ser un miembro de ella.

Entre su licenciatura romana en Estudios Bíblicos (1968) y su doctorado salmantino en Teología Bíblica (1979) Senén ocupó el decenio en servicios académicos y pastorales (prefecto y profesor en el seminario mayor de Valladolid, 1968-1970; profesor en el seminario de Astorga, 1970-1973; rector del colegio español de Múnich, 1973-1976; residencia madrileña en c/ Conde Miranda, 1976-1978; coadjutor en la parroquia madrileña de san Cristóbal y san Rafael, 1978-1979) y, sobre todo, en llevar a término su trabajo doctoral. Puedo testificar - por haber estado yo muy cercano a él- que en ese trabajo Senén se empeñó a conciencia, sabiendo que realizaba una valiosa aportación sobre las tradiciones primitivas acerca de la Resurrección del Señor. No se equivocó, tanto en la valía objetiva de la investigación realizada como por haber creído que ese trabajo tenía que ser completado con otros posteriores, como así fue.

En ese momento de la presentación del trabajo doctoral se cerraba para Senén el círculo de preparación. De entonces en adelante, la cultura bíblica se convirtió en su principal ámbito de vida y de realización.

Todos sabemos lo que los estudios bíblicos conllevan: dominio de idiomas vivos y de lenguas muertas, lectura constante, análisis continuo, creatividad permanente. No sé si por haber sido bilingüe de pequeño, Senén poseía unas especiales condiciones para los idiomas vivos y para las lenguas muertas. Baste, como prueba, un solo detalle. Una vez, me comentó un reconocido biblista español, amigo de Senén y también mío, que era una delicia escuchar a mi hermano las citas, de memoria, del texto bíblico en griego, el cual brotaba de sus labios como brota el agua de una suave y cantarina fuente.

\section{LA CÁTEDRA: UN SERVICIO ACADÉMICO ITINERANTE Y SIEMPRE DISPONIBLE}

Senén realizó un extenso servicio académico en el campo de los Estudios Bíblicos. Fue un servicio a borbotones, a través de cursillos, charlas y conferencias, y un servicio estable, mediante cursos en centros académicos. Del primer grupo -cursillos, charlas y conferencias- hay 
constancia en el archivo personal de Senén, quien propendía a preparar sus intervenciones mediante esquemas bien estructurados y, a veces, mediante desarrollos casi completos. En este momento, me resulta difícil señalar un número para el conjunto de esas intervenciones; en todo caso, tuvo que ser elevado.

El servicio académico estable o reglado fue ejercido por Senén en bastantes centros: seminario mayor de Valladolid (1979-1980 y 19841985), Universidad Pontificia de Salamanca (1980-1984), Universidad Pontificia Comillas (Madrid), en Washington, Universidad Pontificia de México, Centro teológico de Trujillo (Perú), Seminario en Venezuela, Seminario de La Habana, Centro teológico de Las Palmas. En Múnich dirigió el Colegio Español; pero no tuvo propiamente docencia.

Como es fácilmente constatable a partir de los datos precedentes, a Senén le tocó en suerte un servicio académico itinerante. Hubo en su vida intentos de estabilidad, pero no llegaron a una concreción plena. Tales fueron: su presencia en la Universidad Pontificia de Salamanca, que se cortó por decisión del propio Senén al constatar detalles que no le agradaron en relación con la convocatoria de la cátedra de Nuevo Testamento; y, los servicios en Washington y en México, en donde Senén prefirió no insistir para no quitar puestos a aspirantes nativos.

A la precedente constatación sobre la itinerancia académica de Senén hay que contraponer una excepción: él siempre se consideró profesor estable y fijo en el Centro de Estudio Teológico Agustiniano de Valladolid, donde impartió clases entre 1978-1985 y desde 1990 hasta prácticamente el final de su vida. Por su parte, los agustinos han tenido la gentileza de considerar a Senén como uno de los "suyos". Bien se vio en la Eucaristía de corpore insepulto celebrada el día 12 de abril en la iglesia de san Pablo de Salamanca. Presidida por el Sr. Obispo de Salamanca, en una iglesia llena de fieles, la Eucaristía por Senén fue concelebrada por unos 80 sacerdotes, entre los cuales, además de los nutridos grupos de operarios diocesanos, de sacerdotes diocesanos de Salamanca, de dominicos, de redentoristas y de otras instituciones, se distinguía una nutrida representación de agustinos venidos expresamente de Valladolid.

No quiero terminar el comentario de esta foto de Senén en la cátedra académica sin subrayar las notables cualidades que poseía para la comunicación (en clase, en charlas, en conferencias, etc.). Una gran claridad de ideas. Una organización adecuada al tiempo y al espacio. Una dicción suficientemente timbrada y adecuadamente modulada. Una expre- 
sión no leída sino comunicada. Con mirada de listura pero también de comprensión hacia el público.

Un periodista ha visto así al Senén comunicador: "es una gozada escuchar a Senén Vidal. Además del contenido, lo que más me llamó la atención de Senén fue la forma. Este hombre es más que un profesor. Tiene tablas y domina la oratoria. Se explica con talento, con gracia, con entonación. Hasta sabe marcar las pausas y subraya lo más importante con la oportuna elevación de la voz. Sencillo, didáctico, interpelador y... sin leer. Con la conferencia delante escrita, pero sin leerla. Con dominio del escenario, de la voz, de las manos (algo tan difícil) y de la mirada. Una rara avis. Una auténtica gozada" (Juan Manuel Vidal).

\section{LA PARROQUiA: LA PRÁCTICA DE LA EVANGELIZACIÓN CRISTIANA}

Senén reflexionó mucho sobre los procesos de la primera evangelización cristiana, sobre todo la evangelización paulina. Sobre el tema dictó conferencias y escribió libros y artículos (uno de estos en la revista: Naturaleza y Gracia 59 [2012] 261-287).

Pero no solo reflexionó y escribió sobre la pastoral cristiana primitiva; la practicó. También en esto sentí una peculiar envidia de mi hermano. Aunque no he dejado de poner en práctica el deber de la predicación y me he comprometido en acciones pastorales, nunca he tenido una práctica pastoral tan sostenida como la que tuvo Senén.

Por lo menos en cuatro momentos de su vida, Senén estuvo implicado de forma expresa y directa en la práctica pastoral parroquial: en Madrid, parroquia de san Cristóbal y san Rafael (1978-1979); en la ciudad de México (1987-1990); en Majadahonda, Madrid, parroquia del Beato Domingo y Sol (1990-1994); y, sobre todo, en la parroquia de san Pablo en Salamanca (1997-2009).

Fueron los dos últimos lugares los que marcaron la práctica pastoral de Senén. Fue prolongada y muy activa su presencia en la parroquia salmantina de san Pablo. Dejó constancia del final en sus notas personales: "Termino mi servicio en la parroquia de S. Pablo de Salamanca. 12 años en total: desde agosto de 1997 hasta agosto de 2009". Fue en esa iglesia donde le despedimos en Salamanca.

Sospecho que el trabajo pastoral en la parroquia de Majadahonda le aportó a Senén notables satisfacciones. Tuve un atisbo de ello al ver a un grupo de jóvenes parejas, provenientes de esa parroquia, acompañando a 
Senén en el tanatorio y en la eucaristía-funeral de Salamanca el día 12 de abril de 2016. Datos posteriores me lo han corroborado. Ese conjunto de parejas ha constituido un grupo de "Amigos de Senén", con reuniones periódicas. De ellos he recibido documentos y, sobre todo, cariño compartido hacia el hermano que se ha ido.

\section{El LIBRO: UN TELAR PERMANENTEMENTE ABIERTO}

No tengo a mano la bibliografía completa de Senén. Sí tengo a la vista todos sus libros, que me enviaba puntualmente según iban apareciendo. Son unos veinte libros, sin contar los artículos de investigación.

No soy yo quién para juzgar sobre la valía científica de los escritos de mi hermano. Séame, no obstante, permitido considerar a Senén como uno de los grandes conocedores y expositores del pensamiento paulino: por haber tratado de señalar con rigor histórico y filológico los escritos auténticos de Pablo (Las cartas auténticas de Pablo), por haber precisado datos de la trayectoria vital paulina (Pablo. De Tarso a Roma), por haber estudiado su pensamiento teológico (El proyecto mesiánico de Pablo) y su propuesta misionera. Por otra parte, creo que en España no se había hecho un estudio tan preciso sobre la génesis de los escritos juánicos como la que formuló Senén (Evangelio y Cartas de Juan). Considero de gran originalidad, sin parangón en la literatura nacional e internacional, la propuesta de Senén sobre Los tres proyectos de Jesús. Quedé impactado cuando recibí la traducción, con introducciones y notas, del Nuevo Testamento. Varios especialistas dijeron: esta es obra de toda una vida. Como detalle bonito, recuerdo que cada vecino de nuestro pueblo de san Pedro de Trones recibió un ejemplar de este libro, con dedicatoria del autor. Con especial cariño retengo el último libro publicado por Senén: La Resurrección de los muertos. Lo tengo por su confesión de fe (y de esperanza) antes de irse.

A Senén no se le había acabado la tarea. En su telar había proyectos en marcha. Tenía el deseo de poner al día algunos de los textos publicados. Y, sobre todo, proyectaba escribir una Historia del cristianismo primitivo (a partir de los textos neotestamentarios); cuando murió llevaba para la lectura un libro en orden a esa documentación: La guerra de los judíos, de F. Josefo. Lástima que, sirviéndome de la imagen bíblica, la trama haya sido cortada. En este último año, bastantes veces me he que- 
jado ante el Señor: “¿Por qué, Señor, tan pronto, cuando aún tenía trabajo para unos diez años?".

Como rasgo importante de su semblanza, es preciso retener en la figura de Senén su condición de escritor. Si tenía cualidades para hablar, también las tenía para escribir. Sabía lo que quería decir, sabía decirlo y paraba cuando lo había dicho. Esta es la clave de la elegancia del buen escribir en estos contextos de la literatura religiosa.

Senén no fue amigo de "modas" en sus estudios bíblicos; tampoco se quedó en aspectos periféricos. Para sus análisis eligió los textos y los temas esenciales. Los estudió buscando en ellos lo esencial y lo definitivo. Lo hizo con originalidad, sin por ello dejar de conocer lo que otros pensaban.

\section{EL HONDÓN HUMANO: ATISBOS DESDE LOS SIGNOS EXTERNOS}

No caeré en la tentación de querer entrar allí por donde no hay caminos. Como toda persona, Senén también tenía su propio hondón. Además, pertenecía a la estirpe de aquellos que "siendo largos en facellas, son cortos en contallas".

Comienzo por recoger las impresiones de una persona de las que componían el grupo pastoral de la parroquia de Majadahonda y que ahora constituyen la agrupación "Amigos de Senén":

"Senén se dejaba conocer poco; a cada uno nos mostraba una faceta de su ser, de su vida, y era hermético en relación a otros aspectos de su vida o de su persona. Mantenía a sus grupos de amigos en compartimentos estancos y evitaba que coincidiéramos, y que nos encontráramos. Estaba muy a gusto en soledad, consigo mismo; aunque también sabía disfrutar de la buena compañía. A menudo repetía que él era el peor de todos sus amigos; y es cierto que cuidaba poco de las relaciones de amistad; dejaba que fueran los otros quienes le llamaran, le visitaran; pocas veces él tomaba la iniciativa. Cuando quería, podía ser muy duro y exigente (...). Era un hombre muy ordenado y organizado y daba mucha importancia al lenguaje, a la palabra. Buscaba expresiones nuevas, con fuerza, que no estuvieran gastadas, y que reflejaran el esplendor de la vida, de la creación. Con él aprendimos que las palabras en parte tienen capacidad de (re)crear la realidad que representan. Nos felicitaba la Epifanía (y no la Navidad) y nos explicaba todo tan bien, tan clarito, que nos preguntábamos cómo habíamos podido estar años creyéndonos tanta 
mentira, tanto mito (...). Poseía una gran libertad interior. E igual que sabía leer entre líneas supo vivir entre líneas. Se quedó con las ganas de ser papa por un día. Con eso le bastaba, decía, para dedicarse a firmar aboliciones de dogmas y otros impedimentos del Espíritu (...). Le recordaré siempre con mucho cariño" (Mónica Cruz).

He leído los apuntes personales que, a modo de diario muy discontinuo, ha dejado Senén. Me quedan algunas impresiones acerca de lo que pudo ser su hondón más íntimo. Senén se dolía de situaciones que consideraba injustas (tanto sociales como, sobre todo, eclesiales) pero no criticaba a las personas. Senén era lúcido ante la carencia de evidencias sobre el sentido de la existencia; a su pluma venía con frecuencia la pregunta: “¿por qué existe lo que existe? ¿por qué existo yo?”. Al final, terminaba por aceptar la evidencia del existir y se entregaba al misterio de Alguien que lo sustenta todo. He aquí una expresión, en verso, de esa inquietud:

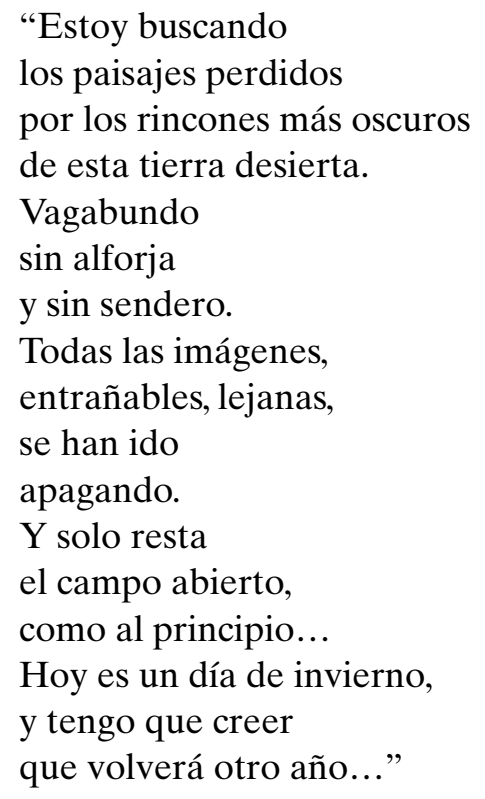

(Roma, 19.1.1966).

El primero de los poemas que se conservan de Senén entreabre la puerta para conocer su instalación más profunda en la realidad:

"Ahora es todo muy sencillo.

Como antes. 
Fueron llegando las cosas, y cada una se colocó en su sitio. ... 'Mira, esto es el árbol, y la fábrica...

Y el sol detrás de las montañas'.

Todo es tan antiguo.

Como siempre".

(Salamanca, 1964).

\section{Peculiaridades de la vivencia religiosa cristiana}

Si es difícil conocer y expresar el hondón de cada persona, lo es más el saber y el formular cómo es su dimensión religiosa. Por lo general, las personas de la generación de Senén no han sido proclives a manifestar sus experiencias religiosas. Esta afirmación es válida para quienes componemos nuestra familia. Habiendo tenido un padre que solía hablar de la religión sin miedo y abiertamente, sus hijos hemos tendido hacia el pudor en las manifestaciones de nuestra propia vivencia religiosa. Senén no quedó al margen de esta regla de familia.

Yo atisbé la dimensión religiosa de Senén a través de sus homilías. Me dio la impresión de que era recia y profunda en las convicciones. Creí advertir que propendía a la parquedad en las expresiones. Pero también me atrevo a pensar que tanto las experiencias como las manifestaciones de su fe cristiana utilizaban cauces de gran libertad, de fecunda creatividad y de declarada actualidad.

Las referencias al Jesús de los evangelios estaban a flor de piel cuando Senén se expresaba en clave religiosa. Tales referencias concretas cobraban un significado de amplia dimensión histórica y hasta cósmica al ser situadas por él dentro de los esquemas paulinos, que Senén tan bien conocía. No constaté en él una querencia especial por la interpretación mistérica y cuasi-mística, de carácter juánico, del misterio cristiano. Conocedor como era de la teología juánica, intuí que le era más cercana la amplia visión paulina del mensaje religioso de Jesús de Nazaret.

\section{LA RESURRECCIÓN COMO HORIZONTE ABIERTO A LA ESPERANZA DE VIDA}

Según he anotado, el último libro publicado por Senén, días antes de su fallecimiento, fue La Resurrección de los muertos (en pronta traducción 
italiana). Ese libro no pudo tener una presentación convencional. Pero, yo me dije a mí mismo que, pudiendo ser interpretado como su testamento, ese libro de Senén no podía carecer de presentación. Se la hice, lo mejor que pude, en la homilía me pronuncié en la Eucaristía funeral de corpore insepulto en Salamanca el día 12 de abril, el siguiente a su muerte.

Nunca pensé tener que hablar en el funeral de Senén. Siempre abrigué la esperanza de que él hablara en el mío. El Señor de la vida y de la historia cambió mis planes. Sacando fuerzas y serenidad de un lugar que yo mismo desconozco, presenté la vida de Senén como un acto de fe en la Resurrección: como una apuesta por el Dios de la Vida frente a tantas prácticas de muerte como surgen dentro de la historia humana.

En el Acto de Reflexión Bíblica y de Oración que tuvimos en recuerdo de Senén, en la Parroquia de Nuestra Señora del Perpetuo Socorro de Madrid (19/V/2016), al que tuvieron a bien asistir una amplia representación de la numerosa colonia de pedrelos (habitantes de San Pedro de Trones) en la capital de España, volví a sintetizar la vida de Senén en su afirmación práctica a favor de la Vida. El Dios de la revelación es Dios de Vida, tanto en la naturaleza como en la historia. La Plenitud de esa vida ha sido anticipada en la Resurrección de Jesús. Así, pues, creer en la Resurrección es abrir el horizonte de la esperanza a una Vida en plenitud.

Mostrar y vivir esa esperanza de vida en la Resurrección de Jesús fue la hermosa tarea de Senén en el breve espacio de tiempo que estuvo en este mundo, tan breve que no llegó a medir 75 vueltas de la tierra alrededor del sol, tal como a él le gustaba medir el tiempo humano.

Si fue breve el tiempo en que gozamos de Senén y si es grande la ausencia que de él sentimos, hay un consuelo que sus hermanos, sobrinos y amigos expresamos con los tres últimos versos de Las Coplas por la muerte de su padre del poeta Jorge Manrique:

"Que, aunque la vida perdió, dejónos harto consuelo su memoria". 